\title{
CULTIVO DO MANGOSTÃo NO BRASIL
}

\author{
CÉLIO KERSULDO SACRAMENTO' ${ }^{1}$ ENIO COELHO JÚNIOR ${ }^{2}$, JOSÉEDMAR URANO DECARVALHO ${ }^{3}$, \\ CARLOS HANS MÜLLER ${ }^{3}$, WALNICE MARIA OLIVEIRA DONASCIMENTO3
}

RESUMO - O mangostão (Garcinia mangostana L.), família Clusiaceae, é considerada a fruta mais saborosa do tropico asiático. Foi introduzido no Brasil em 1935 e atualmente é cultivado principalmente nos estados do Para e Bahia, numa área estimada de 350 ha com uma produção de 300 t. O período de frutificação do mangostanzeiro varia de acordo com as condições climáticas e, no estado do Pará, o principal período de colheita estende-se de janeiro a maio e uma colheita menor ocorre em agosto e setembro. Na Bahia a safra principal é geralmente em março e abril e outra colheita acontece em agosto. Poucas pragas têm sido encontradas em pomares de mangostão e os problemas mais comuns são causados por ácaros, tripes (Thrips sp. ) e abelha arapuá (Trigona spinipes) as quais causam danos na casca do fruto dificultando a colheita. A murcha do mangostanzeiro, doença ainda não encontrada em pomares de mangostão de outros paises, tem sido observada somente em plantas adultas na região sul do estado da Bahia, mas o agente causal ainda não foi identificado. Estouro de vasos, um distúrbio fisiológico no pericarpo do fruto e polpa translúcida são comuns nos frutos em pomares brasileiros. Os frutos são colhidos manualmente, limpos, classificados e colocados em caixas de papelão com dimensões de 21 x 21,5 x 6,5 cm as quais contem de 9 a 20 frutos e são vendidos principalmente em grandes centros urbanos. O mangostão apresenta média de $32,5 \%$ de polpa, $18,17 \%{ }^{\circ}$ Brix e $1 \%$ de acidez. A casca apresenta um grupo de substancias conhecidas como xantonas as quais são utilizadas para produtos farmacêuticos.

Termos para indexação: Garcinia mangostana, produção, fitossanidade, qualidade

\section{GROWING MANGOSTEEN IN BRAZIL}

\begin{abstract}
Mangosteen (Garcinia mangostana L.), family Clusiaceae, is considered the most delicious fruit from the Asiatic tropic. It wass introduced in the Brazil in 1935 and currently is cultivated mainly in the states of Para and Bahia in an area estimated on 350 ha with production of 300 tons. The fructification period of the mangosteen tree varies according to climatic conditions and, in the state of Pará, the principal harvesting season is usually from January to May and a small second crop in August and September. In the state of Bahia the main harvest season is usually from March to April and a second harvesting occurs in August. Few pests have been observed in brazilian mangosteen orchards and the related problems are caused by mite, triphs and trigona bees (Trigona spinipes ) which damage the fruit rind difficulting the harvest. The mangosteen tree wilt, disease not yet observed in orchards of mangosteen in other countries, has been the main problem in adult's mangosteen trees in South of Bahia region. Gamboge disorder, a physical damage in the fruit pericarp, and the translucent pulp also area commons in mangosteen fruits in brazilian orchards. The fruits are harvested manually, cleaned, graded and packed into a 21 x 21.5, $6.5 \mathrm{~cm}$ cardboard box containing from 9 to 20 fruits. The fruits are sold mainly in big urban centers. The mangosteen presents average of $32.5 \%$ of pulp, $18.17^{\circ}$ Brix and $1 \%$ of acidity. The rind has a group of substances known as xanthonas which are utilized by pharmaceutics industries.
\end{abstract}

Index terms: Garcinia mangostana, production, fitossanity, quality

\section{1-Introdução}

O mangostão, originário do arquipélago Malaio, é considerado a fruta mais saborosa do trópico asiático. No Brasil, foi introduzido definitivamente por volta de 1935, na Bahia, e em 1942 no Pará (Donadio et al., 1998; Sacramento, 2001).

No Brasil, o mangostão é cultivado, principalmente, nos Estados do Pará e da Bahia e, em pequena escala, no Espírito Santo e São Paulo. No Pará, a cultura do mangostão está concentrada em área plantada de cerca de 250 hectares, principalmente nos municípios de Santa Isabel do Pará, Benevides, Castanhal, Marituba, Santo Antônio do Tauá e, em menor escala, em Tomé-Açu. Aproximadamente 50\% fazem consócio com outras espécies frutíferas, principalmente açaí, cupuaçu, banana e laranja. Pequenos pomares são também encontrados nos demais Estados da Amazônia, porém sem expressão econômica. Na Bahia, a maior concentração de mangostanzeiros localiza-se no município de Una, em uma área de aproximadamente 80 hectares, sendo cerca de 20 ha distribuídos entre outros municípios do sul da Bahia (Taperoá, Ituberá, Uruçuca, Nilo Peçanha e Tancredo Neves). No Espírito Santo, estima-se uma área de 10 ha nos municípios de Linhares e Castelo, com poucas plantas em estádio de produção. Em São Paulo, no município de Cardoso, foram plantados, em 1995, mais de 10 ha de mangostanzeiros enxertados.

A produção brasileira de mangostão tem variado em função de novas áreas implantadas e da alternância de produção apresentada por essa espécie. Nos anos de 1999, 2000 e 2001, em Una, foram comercializadas, respectivamente, $6.000,10.000$ e 60.000

\footnotetext{
Eng ${ }^{o}$ Agrônomo, DSc., Professor Titular do Departamento de Ciências Agrárias e Ambientais - Universidade Estadual de Santa Cruz- Ilhéus- Ba, CEP 45.650.000 celiosacramento@ig.com.br

${ }^{2}$ Eng $^{\circ}$ Agrônomo, Extensionista do Centro de Ensino e Extensão, CEPLAC-CENEX Escritório Local de Una-BA eniocoelhojr@bol.com.br

${ }_{3}^{3}$ Pesquisador da Embrapa Amazônia Oriental, Belém, PA - CEP 66095-100 - urano@cpatu.embrapa.br, walnice@cpatu.embrapa.br
} 
caixas de 1,4 kg de frutos (Sacramento, 2001). No Estado do Pará, em 2003, foram comercializadas mais de 180 toneladas de frutos de mangostão.

\section{Sistemática, descrição botânica e variedades 4.1 - Sistemática}

O mangostanzeiro pertence à família Clusiaceae, que engloba aproximadamente 1.000 espécies, subordinadas a 47 gêneros, dispersos em regiões tropicais e subtropicais do mundo (Barroso et al., 2002; Brummit, 1992; Cronquist, 1981). No Brasil, essa família está representada por cerca de 21 gêneros e 183 espécies, distribuídas nas diferentes regiões do País (Barroso et al., 2002), das quais se destacam o abricoteiro (Mammea americana L.), o bacurizeiro (Platonia insignis Mart.), o bacuriparizeiro (Rheedia macrophylla (Mart.) Pl. et Tr.), o bacuparizeiro (Rheedia gardneriana Miers. ex. Pl. et Tr.) e, de forma mais secundária, o bacuriparizeiro liso (Rheedia brasiliensis (Mart.) Pl. et. Tr.) e o bacurizinho (Rhedia acuminata (R. et. Tr.) Pl.et.Tr.). O abricoteiro é de origem antilhana, e as demais espécies são nativas do Brasil. Dessas, somente o mangostão é cultivado comercialmente, sendo as outras espécies ainda exploradas em escala extrativista.

Outra espécie do mesmo táxon genérico (Garcinia cochinchinensis Choisy.), conhecida como falso-mangostão, garcínia ou mangostão-amarelo, sem nenhuma expressão econômica, é encontrada em pomares domésticos no Brasil e tem sido freqüentemente confundida com o mangostão ( $G$. mangostana L.), em particular na fase jovem.

No Brasil, é conhecido como "mangostão" ou "mangustão", entretanto os produtores de Una utilizam comercialmente o nome "mangostin"(aportuguesamento do inglês "mangosteen"). Os produtores do Pará também já utilizaram essa denominação, mas, nos últimos anos, têm adotado o nome inglês "mangosteen" para comercialização dos frutos que se destinam aos mercados das regiões sudeste e centro-oeste do Brasil.

O fruto é uma baga subglobosa, de 4 a $9 \mathrm{~cm}$ de diâmetro transversal e 3,6 a 6,5 cm de altura e peso de 30 a 240 g, com cálice persistente e cicatriz do estigma lobada, pericarpo purpúreo, duro e grosso, de espessura entre 0,5 a $1,0 \mathrm{~cm}$, o qual contém resina amarela. A parte comestível é formada por quatro a oito segmentos carnosos brancos translúcidos e com sabor bastante delicado. O número de sementes por fruto varia de zero a três, sendo, mais freqüentemente, encontrados frutos com 1 semente.

As sementes de mangostão são apomíticas, ou seja, na sua formação, não há envolvimento de processo sexual, são de formato variável e apresentam comprimento entre $1,7 \mathrm{~cm}$ e 2,0 cm (Enoch, 1979). Quando o fruto está completamente maduro, o teor de água das sementes ainda é bastante elevado, geralmente entre $57,7 \%$ e $67,4 \%$. O peso da semente varia entre $0,31 \mathrm{~g}$ e $1,8 \mathrm{~g}$, com média de $0,87 \mathrm{~g}$.

\section{5-Ecologia}

Nos diversos países produtores, o mangostanzeiro é cultivado em áreas onde o clima é quente e úmido, com chuvas bem distribuídas durante o ano, sendo as áreas potenciais de cultivo do mangostão localizadas até a latitude de $18^{\circ}$ em locais quentes, livres de geadas. Essa frutífera pode ser cultivada em locais acima de $1.000 \mathrm{~mm}$, mas o crescimento é melhor em altitudes próximas ao nível do mar.

A temperatura ideal, para o cultivo, situa-se entre $25^{\circ} \mathrm{C} \mathrm{e}$ $30^{\circ} \mathrm{C}$, com umidade relativa acima de $80 \%$. Temperaturas abaixo de $5^{\circ} \mathrm{C}$ e acima de $38^{\circ} \mathrm{C}$ podem ser letais e, abaixo de $20^{\circ} \mathrm{C}$, podem retardar o crescimento do mangostanzeiro. Como planta de trópico úmido, essa frutífera requer precipitação acima de $1.270 \mathrm{~mm}$ bem distribuída.

Em Una-BA (latitude $15^{\circ} 17^{\prime} \mathrm{S}$ e longitude $39^{\circ} 4^{\prime} \mathrm{W}, 50 \mathrm{~m}$ acima do nível do mar.), onde se concentra a maior área produtora de mangostão da Bahia, a temperatura média é de $23,6^{\circ} \mathrm{C}$, máxima média de $28,3^{\circ} \mathrm{C}$ e mínima média de $20,3^{\circ} \mathrm{C}$, com umidade relativa de $85,1 \%$ e precipitação anual de $1.800 \mathrm{~mm}$, bem distribuída.

No Pará, os municípios produtores de mangostão (Benevides, Castanhal, Santa Isabel do Pará, Marituba e Santo Antônio do Tauá) estão situados próximos a Belém, capital do estado, onde a temperatura média é de $25,9^{\circ} \mathrm{C}$, precipitação anual de $2.761 \mathrm{~mm}$. De acordo com Muller et al. (1991), essas regiões apresentam dois períodos distintos: um período mais chuvoso, que vai da segunda quinzena de dezembro a junho, e outro, menos chuvoso, de julho à primeira quinzena de dezembro, caracterizado pela ocorrência de chuvas de grande intensidade, mas de curta duração, com períodos mais secos entre outubro e novembro.

Com relação ao tipo de solo, o mangostão adapta-se bem em solos profundos argilo-arenosos, bem drenados e, preferivelmente, com alto teor de matéria orgânica. Em Una (BA), o mangostão é cultivado em Latossolos Vermelho-Amarelos, considerados de baixa fertilidade natural. No Estado do Pará, os plantios estão estabelecidos em Latossolo Amarelo.

\section{1 - Aspectos fenológicos da floração e frutificação}

A época de florescimento do mangostanzeiro varia de acordo com as condições climáticas, podendo ser concentrada em um ou mais períodos durante o ano. $\mathrm{O}$ mangostanzeiro apresenta tendência de florescimento em anos alternados, e a frutificação varia de planta para planta. As plantas florescem após o crescimento de fluxos vegetativos e principalmente após um período de estiagem. $O$ florescimento pode ocorrer duas vezes ao ano, dependendo das condições climáticas, manejo e do número de fluxos vegetativos. O período entre a iniciação floral e a antese é de 25 dias e da antese até o fruto maduro 100 a 120 dias (Yaacob e Tindall, 1995).

No Pará, em particular na microrregião Belém, onde se concentram os principais pomares de mangostanzeiros, quando a precipitação é normal, ocorre uma pequena floração, geralmente, no período de junho a agosto, e que é responsável pela pequena safra verificada entre outubro e dezembro. A safra principal ocorre entre janeiro e maio, e é resultante da floração que ocorre entre setembro a janeiro. Resultados referentes a dez safras consecutivas evidenciaram que, aproximadamente, $80 \%$ da produção de mangostão, na microrregião Belém, se verifica no período de janeiro a junho. A "safrinha”, que ocorre no segundo semestre, é responsável por 20\% da produção (Figura 1). 
Em levantamento efetuado na área produtora do município de Una-BA, verificou-se que, nos anos de 1999 e 2000, as maiores produções ocorreram nos meses de março e abril e, no ano de 2001, além desses dois meses, houve um pico de produção em agosto (Sacramento, 2001) (Figura 2).

\section{6-Propagação}

Nos principais países produtores de mangostão, a formação de mudas é feita sexuadamente, considerando-se que as sementes dessa espécie são apomíticas e, portanto, as plantas não apresentam variabilidade genética. Quanto à germinação, as sementes perdem rapidamente a viabilidade e não podem ser conservadas pelos métodos convencionais de armazenamento, que têm como pressupostos básicos a redução do teor de água e o armazenamento em baixas temperaturas. Alguns procedimentos têm sido indicados para manter a viabilidade das sementes por períodos que possibilitem o transporte das sementes de um local para outro. Normalmente, é recomendada a estratificação das sementes em substrato umedecido com água. O substrato para estratificação das sementes pode ser fibra de coco, pó de serragem curtida ou vermiculita. Alternativamente, as sementes podem ser conservadas dentro dos frutos ou em sacos de polietileno por períodos de até 35 dias (Müller et al., 1991). Em condições favoráveis de temperatura e umidade, a quase totalidade das sementes germina entre 10 e 20 dias após a semeadura (Müller et al., 1995). (Figura 3)

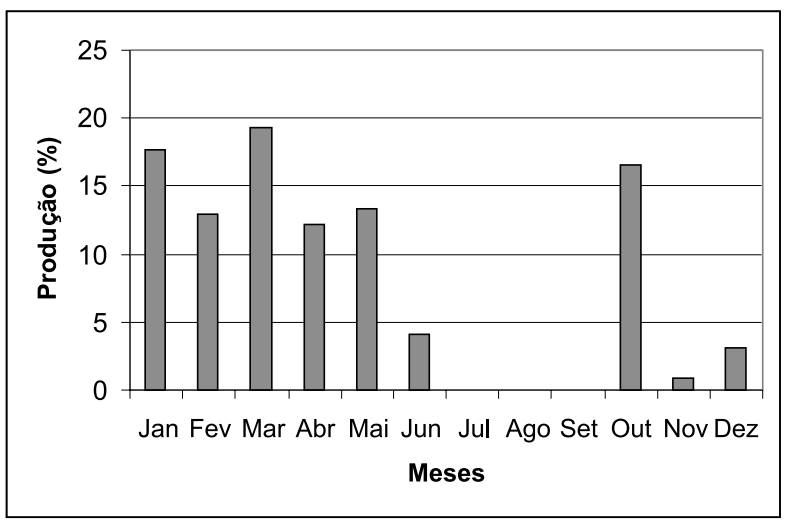

FIGURA 1 - Distribuição percentual da produção de frutos de mangostão durante o ano, na microrregião BelémPA.

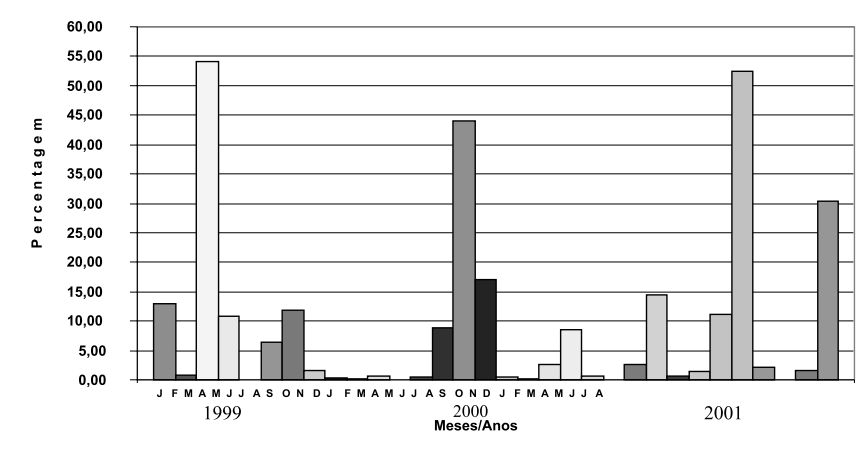

FIGURA 2 - Distribuição percentual de caixas de mangostão comercializadas por produtores de Una-BA, de 1999 a 2001 (até agosto) (Sacramento, 2001).

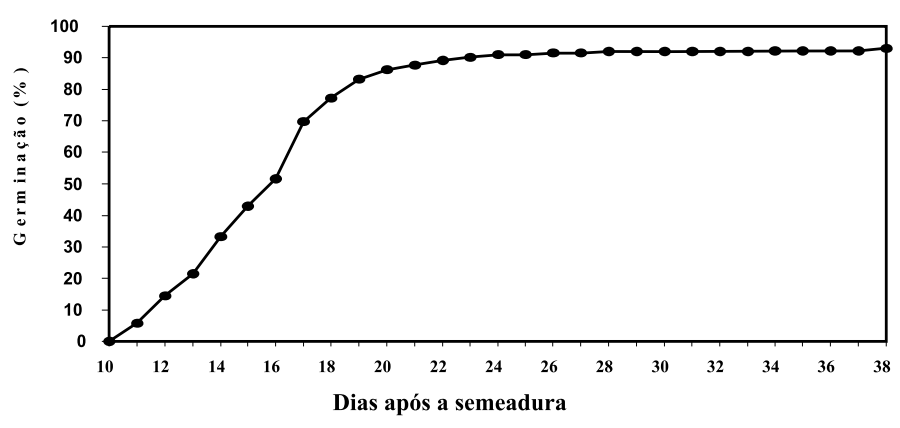

FIGURA 3 - Curva de germinação de sementes de mangostão (dados não publicados: Urano de Carvalho)

Após o transplantio, as mudas devem ser mantidas em local sombreado, com $50 \%$ de luminosidade. Os tratos culturais do viveiro consistem na manutenção da umidade por meio de irrigações e na eliminação periódica de plantas daninhas que crescem no substrato.

Müller et al. (1989) recomendam adubações foliares com produtos que tenham na formulação macro e micronutrientes e a aplicação preventiva, a cada dois meses, de fungicidas à base de cobre (3 g.L $L^{-1}$ de água), mais Mancozeb (2 g.L L $\left.^{-1}\right)$, para controlar eventuais doenças que possam ocorrer nos viveiros.

Quando bem manejada, após dois anos de viveiro, a muda apresenta 30 a $40 \mathrm{~cm}$ de altura e está pronta para o plantio definitivo ou para ser utilizada como porta-enxerto.

O mangostanzeiro pode ser propagado por enxertia de garfagem no topo em fenda cheia, embora os métodos de enxertia em fenda lateral e de encostia também possam ser utilizados. No processo de enxertia, são usadas, como porta-enxertos, mudas de mangostão, com dois anos de idade. Os garfos ou enxertos devem ser retirados de ramos ortotrópicos (centrais), pois os ramos laterais formam plantas com crescimento lateral (plagiotropia). Após o processo de enxertia, o garfo e parte do porta-enxerto devem ser envolvidos por um saco transparente (câmara úmida), a fím de evitar a evaporação da água e o ressecamento do enxerto. As mudas recém-enxertadas devem ser mantidas em local sombreado. Embora a propagação assexuada reduza em até dois anos o período vegetativo, na prática, tem sido observado que plantas propagadas por semente apresentam crescimento mais vigoroso e, quando adultas, suplantam em produção aquelas originadas de mudas enxertadas. Desse modo, a enxertia praticamente não tem sido utilizada na implantação de pomares comerciais. Nos outros países produtores, também não se utiliza a propagação vegetativa na formação de pomares comerciais.

\section{7-Implantação do pomar}

No preparo da área para plantio de mangostão, a maior preocupação tem sido a utilização de consórcio com outras plantas que possam, ao mesmo tempo, fornecer sombra, necessária ao seu desenvolvimento inicial, e também proporcionar alguma renda durante o seu período vegetativo (Sacramento e Coelho Jr., 2005).

Em termos de sombra, a bananeira constitui uma excelente alternativa para o desenvolvimento durante os quatro primeiros 
anos do mangostanzeiro. Outras espécies de produção precoce (pimenteiras, mamoeiros, araçazeiros, pitangueiras) também podem ser utilizadas. Não é aconselhável o consórcio do mangostãozeiro com espécies perenes que possam causar competição durante a fase produtiva, pois essa frutífera produz melhor a pleno sol. No Brasil, o mangostão tem sido consorciado com outros cultivos tropicais em sistemas agroflorestais, como rambotã, cupuaçu, graviola, mas embora ecologicamente haja benefícios pela proteção do solo, fisiologicamente ocorre competição de copas por luz, causando baixa frutificação e produção. Mangostanzeiros implantados em cacauais também não apresentaram bom desenvolvimento. Plantas da família Arecaceae (açaizeiro, pupunheira, coqueiro) possuem um sistema radicular muito agressivo e, quando plantadas perto do mangostanzeiro, afetam severamente o seu crescimento e, por isso, não são recomendadas como consórcio (Sacramento, 2001).

Os espaçamentos utilizados para o cultivo do mangostão, no Brasil, variam de 6 × 6 a $10 \times 10 \mathrm{~m}$, porém, em espaçamentos menores, observa-se competição entre copas a partir do $12^{\circ}$ ano de plantio.

\section{8 - Tratos culturais \\ 8.1 - Adubação}

$\mathrm{Na}$ região sul da Bahia, a maioria dos produtores não faz uso de análise de solo para adubação do mangostanzeiro, e, desse modo, cada produtor aplica diferentes tipos e quantidades de adubo, verificando-se, entretanto, grande preocupação com aporte de matéria orgânica através de esterco bovino, geralmente incorporado em valas abertas na projeção da copa.

Em áreas de produção no Estado do Pará, recomendamse aplicações de $200 \mathrm{~g} /$ planta de cloreto de potássio, no início da floração, e mais duas aplicações com intervalos de 45 dias, com objetivo de reduzir o sintoma fisiológico conhecido como "estouro dos vasos lactíferos" ou "empedramento de frutos". Após o término da safra, recomenda-se a aplicação de $300 \mathrm{~g}$ de NPK, formulação 10-28-20 e mais 40 litros de cama de aviário por planta adulta (Müller, C.H. informações pessoais).

Adubações desequilibradas podem causar sérios problemas no desenvolvimento do mangostanzeiro. Nas regiões produtoras do Pará e da Bahia, têm sido verificados casos de redução acentuada do limbo foliar e do comprimento do entrenó das plantas devido à nutrição desbalanceada, provavelmente, entre zinco e ferro. Na Bahia, tem sido verificado grande percentual de frutos com problemas de empedramento, os quais podem ser causados por deficiência de potássio.

\section{2-Irrigação}

Nas regiões brasileiras, onde o mangostão é cultivado comercialmente, a quantidade e a distribuição das chuvas têm sido suficientes para a produção satisfatória de frutos, entretanto alguns produtores possuem sistemas de irrigação para utilização em casos de ocorrência de estiagem prolongada. Os sistemas de irrigação localizada (microaspersão e gotejamento) proporcionam a aplicação da água na área de concentração das raízes, em pequenas quantidades e alta freqüência, sendo, portanto, os mais apropriados para o cultivo do mangostanzeiro.

\section{4-Poda}

O mangostanzeiro é conduzido praticamente sem poda até o $3^{\circ}$ ano de plantio. A partir daí, efetua-se a eliminação dos ramos próximos ao solo, para facilitar os tratos culturais e, também, para evitar que estes sirvam de acesso para ratos e outros roedores, os quais danificam os frutos. Em plantas adultas, tem sido efetuada eliminação de ramos finos, doentes e secos no interior da copa. Alguns produtores eliminam ramos alternados em plantas adultas (com mais de 20 anos) para favorecer a aeração e a luminosidade, e estimular a frutificação no interior da copa. Outros produtores podam o ápice da planta para permitir maior luminosidade no interior da copa, mas essa prática não tem mostrado resultados satisfatórios.

\section{5-Raleamento de frutos}

A maior frutificação do mangostanzeiro ocorre nos ápices dos ramos expostos à luminosidade. Geralmente cada ápice de ramo apresenta apenas um fruto, entretanto podem ocorrer dois ou mais frutos por ápice ou mesmo em gemas perto do ápice, causando competição e gerando frutos de menor tamanho. Neste caso, o produtor deve manter somente o fruto localizado no centro. O raleamento tem como objetivo reduzir o número de frutos na árvore para estimular a produção de frutos maiores e com peso médio de 130 a 140 gramas, os quais obtêm melhores preços no mercado. Nesse caso, a eliminação do excesso de frutos deve ser feita logo após a antese, pois, a partir de determinado estágio de desenvolvimento do fruto, não há nenhuma vantagem na sua eliminação.

\section{9 - Pragas, doenças e danos fisiológicos}

No Brasil, são observados os seguintes problemas com pragas, doenças e danos fisiológicos:

\section{1-Pragas}

Abelha-arapuá ou abelha-cachorro (Trigona spinipes)

Essas abelhas danificam os botões florais e o fruto em crescimento, causando ferimentos na sua superfície. Dessas feridas, exsuda uma resina amarela, conferindo ao fruto um aspecto rugoso Os danos causados pelas abelhas-arapuá são externos e não afetam a parte comestível dos frutos, entretanto estes ficam com o aspecto visual comprometido para o comércio em mercados mais exigentes. A medida mais viável de controle dessa praga consiste na eliminação de seus ninhos, num raio de $500 \mathrm{~m}$ do pomar, entretanto essa não é uma prática de fácil execução.

\section{Ácaros (Tetranichus sp.)}

O mangostão atacado por ácaros apresenta, externamente, aspecto ferruginoso. Embora não haja dano interno e não seja limitante à comercialização, o aspecto ferruginoso dificulta a colheita e a classificação dos frutos quanto ao estágio de maturação (Figura 4). Em outras frutíferas, recomendam-se inspeções periódicas para detectar a presença de ácaros, utilizando-se de uma lente de aumento $(10 \mathrm{x}) \mathrm{e}$, em caso de danos econômicos, tem sido utilizada a aplicação de acaricidas específicos e enxofre. No caso do mangostãozeiro, apesar dos 
danos causados, não tem sido aplicado nenhum produto para controle dos ácaros e, especificamente no caso de aplicação do enxofre, pode comprometer a qualidade do fruto, na comercialização, pelo odor desse produto químico.

\section{Tripes (Thrips sp.)}

$\mathrm{O}$ ataque de tripes ocorre em plantios do Pará, sendo a maior frequiência no período de estiagem, e os sintomas nos frutos atacados assemelham-se aos danos provocados por ácaros.

Além dessas pragas, em outros países produtores, as formigas, cochonilhas, morcegos, ratos e nematóides têm sido relatados como problemas no cultivo do mangostãozeiro.

\section{2-Doenças \\ Murcha do mangostanzeiro}

$\mathrm{Na}$ região sul da Bahia, a murcha do mangostanzeiro tem se constituído no principal problema fitossanitário dessa espécie frutífera. A doença tem sido detectada principalmente em mangostãozeiros frutíferos, e as plantas atacadas caracterizam-se por apresentar sintomas iniciais de amarelecimento, queda de folhas e murchamento dos frutos. Em menos de 1 mês, após os primeiros sintomas, a planta fica com aspecto de queimada e reduzida apenas a ramos secos (Figura 5). $\mathrm{O}$ ataque tem sido observado em mangostãozeiros frutíferos nos municípios de Una, Taperoá, Ituberá e Tancredo Neves, tanto em plantios comerciais como em plantas isoladas. Amostras de raízes de plantas atacadas foram analisadas na Clínica de Fitopatologia do Centro de Pesquisas do Cacau (CEPEC/ CEPLAC) e, de acordo com Bezerra et al. (2003), foram encontrados diversos fungos associados às raízes de mangostãozeiros atacados: Mycoleptodiscus sp, Lasiodiplodia theobromae, Ganoderma philippi, Fusarium solani, Phytophthora sp., Beltrania e Cilindocladium sp., Xylaria sp., Cytospora sp. e Rosellinia sp. Não há resultados conclusivos, estando o problema em observação. Mudas plantadas nas covas onde houve morte do mangostanzeiro, não apresentam nenhum sintoma da doença na fase vegetativa.

\section{Queima-do-fio (Koleroga noxia)}

Essa doença tem sido relatada em plantios de mangostão do Pará, não havendo registros de sua ocorrência em plantios na Bahia. De acordo com Almeyda e Martin (1976), a queima-do-fio é comum em mangostãozeiros cultivados em Porto Rico, sendo encontrada também em cacaueiro, cafeeiro e seringueira, ocorrendo quando há excesso de sombra e umidade. A fase vegetativa do fungo ocorre como um filamento, que primeiro começa sobre os ramos menores. Quando o fungo alcança as folhas, forma um filme esbranquiçado sobre o limbo e então os ramos jovens são cobertos pelo filamento. Alguns frutos, principalmente aqueles em desenvolvimento, são cobertos com o filamento e secam. As folhas começam a perder o brilho, tornamse marrom-claras e eventualmente de coloração marrom-escuras ou mesmo negras. Neste estágio, elas se desprendem do ramo, porém permanecem suspensas por um fio semelhante à teia de aranha, o que constitui a melhor característica para o seu diagnóstico (Figura 6). Adoença ocorre principalmente em plantas de crescimento vegetativo abundante, principalmente em áreas muito sombreadas e em ambiente úmido. Esse fato sugere que o melhor remédio para a doença é a remoção de parte do sombreamento e a drenagem do solo em volta da planta para reduzir a umidade. Como medidas culturais, Nunes e Nunes (1995) recomendam a eliminação e a queima das partes atacadas, seguidas de pulverização semanal com fungicidas à base de oxicloreto de cobre (150g i.a /100 l de água).

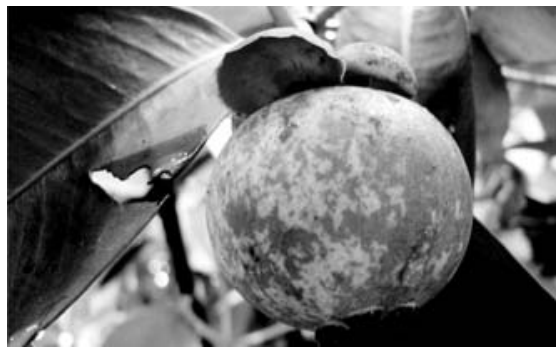

FIGURA 4 - Mangostão danificado por ácaros (Foto C.K.Sacramento)

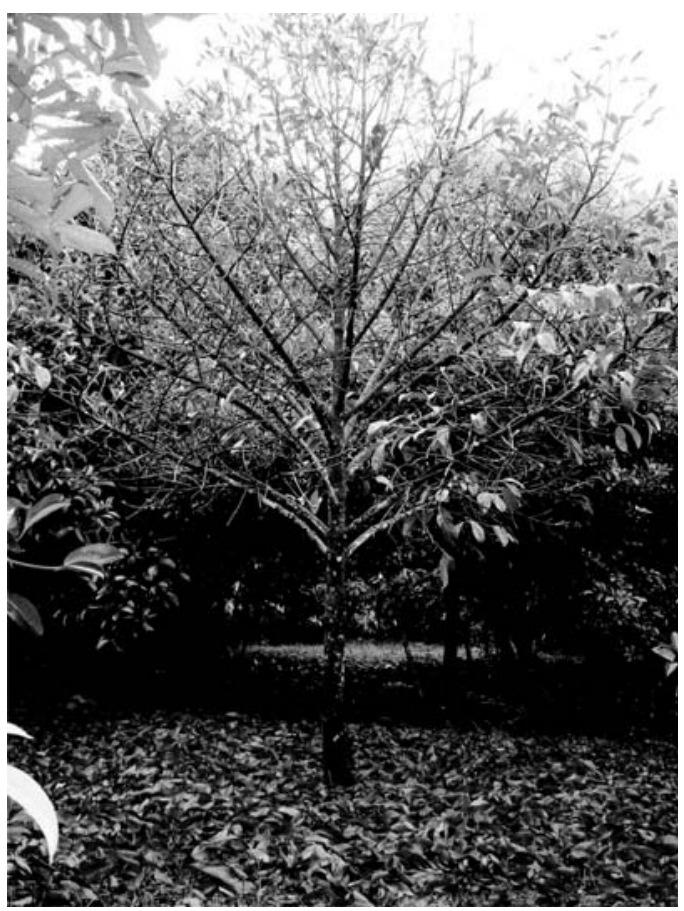

FIGURA 5 - Murcha do mangostãozeiro (Foto C.K.Sacramento)

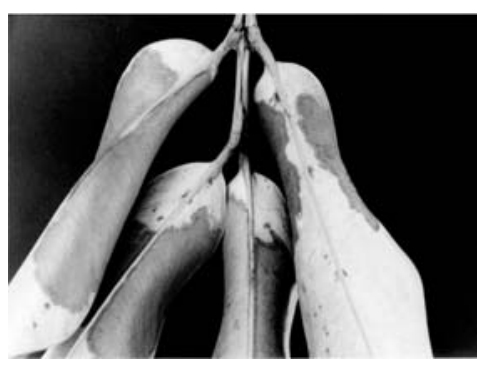

FIGURA 6 - Folhas do mangostanzeiro com sitomas de ataque de queima-do-fio (Foto: Urano de Carvalho) 


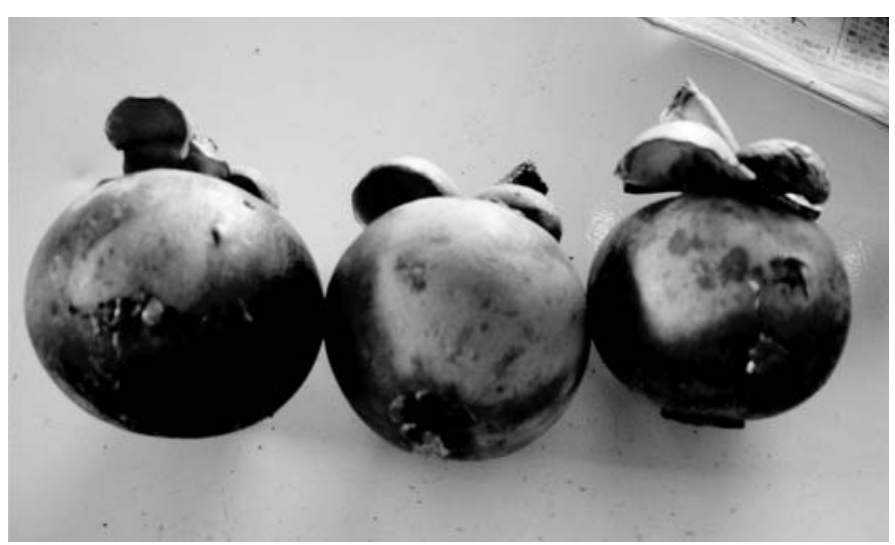

FIGURA 7 - Frutos do mangostanzeiro apresentando estouro de vasos lactíferos ou empedramento. Foto: C.K. Sacramento.

\section{3-Danos fisiológicos \\ 9.3.1 - Estouro de vasos lactíferos ou empedramento dos frutos}

É uma desordem fisiológica que ocorre em frutos em estágio de maturação e caracteriza-se por manchas amarelo-claras e brilhantes na parte externa. No local da mancha amarela, o pericarpo torna-se duro e, quando partido, apresenta coloração marrom, ocorrendo internamente exsudação de uma resina amarela conferindo sabor amargo ao arilo (Figura 7). Ramos e frutos afetados podem exsudar uma resina amarela, que é responsável pela descoloração e mudança de sabor. Esse problema tem ocorrido, principalmente, quando há excesso de chuvas seguido por breves períodos de estiagem, porém o assunto carece de pesquisa. Em épocas de muita ocorrência de chuvas, tais problemas podem comprometer até $40 \%$ dos frutos produzidos.

\subsection{2. - Frutos com polpa translúcida}

Conforme Pankasemsuk el al. (1996), frutos contendo polpa translúcida apresentam significativamente maior conteúdo de água na casca (65\%) e na polpa (82\%) do que os frutos normais (63 a 80\%, respectivamente). Esses autores verificaram que a gravidade específica dos frutos com polpa translúcida foi maior que 1, e da polpa dos frutos normais foi menor que 1. Frutos com polpa translúcida apresentaram concentração mais baixa de sólidos-solúveis e percentagem de acidez titulável que os frutos normais. O problema de polpa translúcida está relacionado com o excesso de umidade.

\section{0- Floração e frutificação}

Em condições de clima e solo favoráveis e manejo adequado, o mangostanzeiro pode iniciar a frutificação a partir de quatro anos (planta enxertada) ou seis anos (pé-franco), em ambos os casos, após o plantio de mudas de 2 anos de idade.

A produção do mangostanzeiro varia, nos diversos países produtores, em função das condições edafoclimáticas, manejo e idade da planta, situando-se entre 200 e 2.000 frutos por planta. No Brasil, são observados casos de produção de até 1.500 frutos por árvore, entretanto, mais importante é a produção de frutos graúdos, com peso médio acima de $100 \mathrm{~g}$. Desse modo, em mangostanzeiros acima de 15 anos, em espaçamento de 10 x 10 metros, pode-se considerar como boa produção 600 frutos por planta, o que resultaria em uma produtividade de 6 t.ha ${ }^{-1}$.

\section{1- Produção e colheita}

A colheita representa um alto custo no cultivo do mangostão, pois os frutos têm de ser colhidos manualmente e no ponto ideal de maturação para atender às exigências do seleto mercado consumidor. O mangostão atinge o ponto de colheita entre 120 e 150 dias após a floração, e o período de colheita estende-se de 6 a 12 semanas.

O ponto de colheita baseia-se na intensidade de coloração do pericarpo, e o estágio apropriado, para comercialização em mercados distantes, é quando os frutos apresentam pequenas manchas de cor rósea ou coloração rosa-clara (Figura 8). Frutos colhidos antes desses estágios apresentam excessiva exsudação de látex no pedúnculo e sabor inferior quando amadurecem. $\mathrm{O}$ fruto, quando maduro, apresenta coloração arroxeada e, se não for colhido, desprende-se da árvore, sofrendo danos ao cair ao solo. Desse modo, a colheita precisa ser efetuada de duas a três vezes por semana.

Os frutos são colhidos manualmente, com o pedúnculo e as sépalas e, devido à altura do mangostanzeiro, na maioria das vezes, o colhedor, munido de um embornal preso ao corpo, necessita subir na árvore ou utilizar escadas para colher os frutos localizados em determinadas partes dos ramos. Frutos localizados nas partes mais altas da copa são colhidos com o auxilio de uma cesta, tipo coador, com capacidade para três frutos, presa na ponta de uma vara ou um tubo de PVC de $100 \mathrm{~mm}$ onde os frutos deslizam e são coletados na parte terminal.

A colheita deve ser feita com o máximo cuidado, pois queda de alturas superiores a $20 \mathrm{~cm}$, em solo duro, danifica o fruto, inviabilizando-o para comércio em mercados mais exigentes.

\section{2-Classificação, embalagem e armazenamento 12.1- Classificação e embalagem}

Os frutos destinados à comercialização nos grandes centros são previamente selecionados quanto aos aspectos de maturidade, problemas de endurecimento, manchados e danificados. A seguir, cada fruto é submetido a uma limpeza debaixo das sépalas, utilizando-se de um pincel com cerdas de consistência média. Tal cuidado visa à eliminação de formigas, aranhas e lagartas que, freqüentemente, se alojam debaixo das sépalas. Em pomares sujeitos à poeira, os frutos são limpos com pano umedecido.

Após a limpeza, os frutos são classificados por tamanho, com base no diâmetro transversal, em classes que variam de 9 a 20. Essa classificação é em função da quantidade de frutos, de diâmetros semelhantes, que cabem, dispostos numa única camada, em caixas de papelão de dimensões internas de 21 x 21,5 $\mathrm{cm}$ de comprimento e $6,5 \mathrm{~cm}$ de altura, com quatro aberturas de 2,8 cm de diâmetro (Figura 9). Tal classificação, cujas médias de diâmetro são apresentadas na Tabela 1, é feita manualmente e não leva em consideração o peso dos frutos. Os frutos com classificação nove até 12 apresentam peso acima de $100 \mathrm{~g}$ e geralmente obtêm os melhores preços no mercado. De acordo 
com levantamento efetuado por Sacramento et al. (2003), em 17.951 caixas comercializadas nos anos de 2000 e 2001 foi verificado que $89,33 \%$ foram representadas pela soma dos tipos $12(33,08 \%), 14(26,91 \%) 10(16,58 \%)$ e $16(12,76 \%)$.

Após a classificação, os frutos são envolvidos individualmente com lenço de papel branco (Figura 9) e recebem um selo da associação de produtores. A seguir, são acondicionados nas caixas, as quais são carimbadas com identificação da classificação e o número do produtor associado. As caixas são, então, amarradas em lotes de cinco ou seis e enviadas para o aeroporto.

\section{2-Armazenamento}

Quando os frutos se destinam aos mercados mais distantes ou para exportação, é importante reduzir a sua taxa de respiração. O mangostão é um fruto climatérico e, quando armazenado a $25^{\circ} \mathrm{C}$, produz alta taxa de etileno e baixa taxa de dióxido de carbono. Yaacob e Tindall (1995) relatam que os frutos armazenados em caixas de papelão à temperatura ambiente podem manter a qualidade por mais de quatro semanas e que o armazenamento de frutos maduros a temperaturas de $4^{\circ} \mathrm{C}$ a $8^{\circ} \mathrm{C}$ pode prolongar o tempo de prateleira. Esses autores afirmam que a temperatura de $13^{\circ} \mathrm{C}$, entretanto, provou ser mais favorável para armazenar e manter o padrão de qualidade, sendo a temperatura ideal para o transporte dos frutos. Os frutos frescos podem ser comercializados em prazos acima de 21 dias após a colheita, desde que seja providenciada alguma forma de mantêlos armazenados a baixas temperaturas.

\section{3 - Comercialização}

A maior parte dos frutos, produzidos durante a safra na Bahia e no Pará, é geralmente enviada para comercialização em São Paulo (CEAGESP), Rio de Janeiro e outras capitais do Sudeste brasileiro. Na Bahia, os frutos são embarcados em avião, no aeroporto de Ilhéus, duas vezes por semana.

Nas feiras e supermercados regionais, são comercializados os frutos excedentes ou muito maduros para transporte a longas distâncias e os frutos pequenos, manchados ou também quando ocorre redução dos preços devido à superprodução ou coincidência entre as safras da Bahia e Pará.

Os frutos produzidos no Pará são comercializados principalmente no Estado de São Paulo. Devido a distância entre os municípios produtores paraenses e a Capital paulista e, também, à concentração da safra, quando os preços caem, o frete por avião torna-se economicamente inviável. Quando isso acontece, o mangostão paraense tem sido transportado junto com outras frutas (mamão, coco e maracujá), em caminhões sem refrigeração. $\mathrm{O}$ gasto de 55 horas, no trajeto entre os dois estados, tem feito com que os frutos cheguem ao destino com a maturação relativamente adiantada, reduzindo, assim, o seu tempo de comercialização.

Com relação ao mercado internacional, a exportação de mangostão ainda é limitada devido aos frutos serem hospedeiros de mosca-das-frutas. O comércio de mangostão tem sido feito pelos produtores asiáticos para mercados europeus, onde não há exigência de desinfestação para mosca-das-frutas. Os frutos

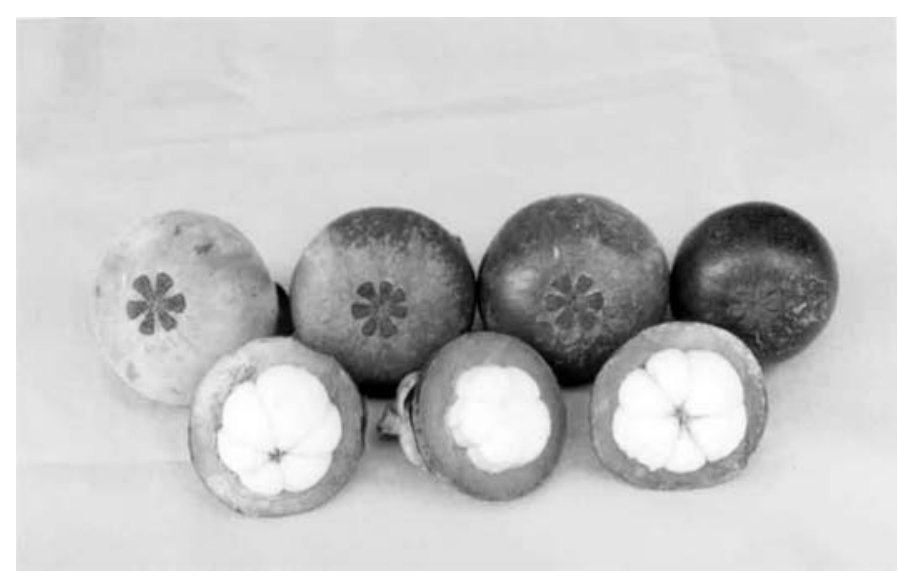

FIGURA 8 - Mangostão em vários estágios de maturação. Foto: C.K.Sacramento.

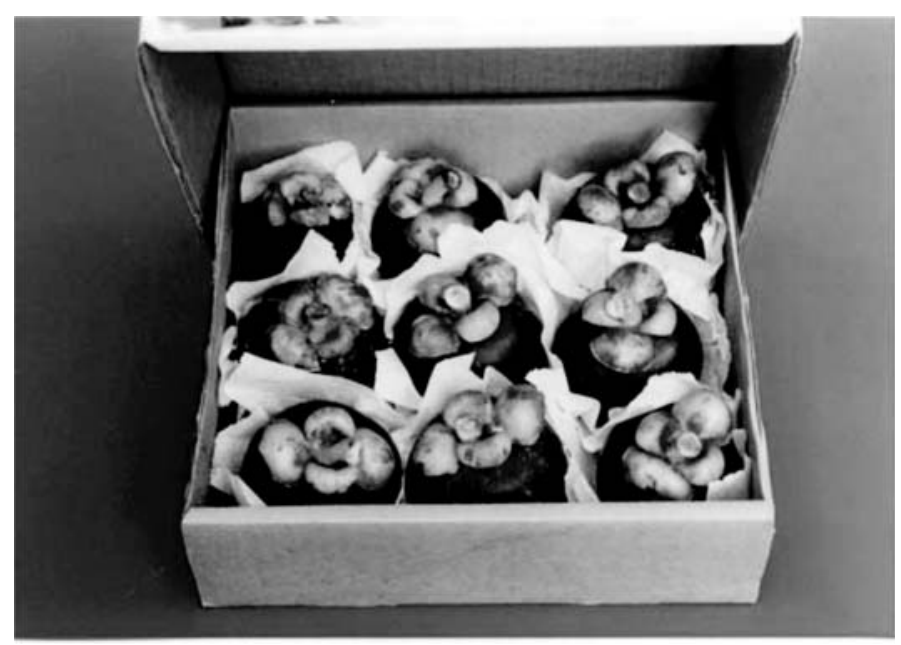

FIGURA 9 - Frutos embalado para comercialização. Foto: Urano de Carvalho.

TABELA 1 - Tipo, diâmetro e peso médio de mangostão de acordo com a classificação adotada por produtores de Una-BA, para número de frutos em caixas de $21,0 \times 21,5 \times 6,5 \mathrm{~cm}$ (Sacramento, 2001).

\begin{tabular}{|c|c|c|}
\hline Tipos de frutos & Diâmetro transversal $(\mathrm{cm})$ & Peso $(\mathrm{g})$ \\
\hline 9 & 6,9 & $147 \mathrm{a} 186$ \\
10 & 6,4 & 132 a 146 \\
11 & 6,2 & 120 a 135 \\
12 & 6,0 & 100 a 123 \\
14 & 5,4 & 80 a 98 \\
16 & 5,2 & 66 a 80 \\
18 & 5,0 & 50 a 66 \\
20 & 4,8 & $45 \mathrm{~g}$ a 50 \\
\hline
\end{tabular}


classificados são, então, congelados inteiros e embarcados para o local de destino. Na Tailândia, foram desenvolvidas máquinas para cortar o pericarpo do mangostão e, dependendo do tamanho do fruto, tais equipamentos têm a capacidade para corte de 216 a 413 frutos por hora.

\section{4 - Usos e composição}

O mangostão é utilizado, principalmente, como fruta fresca, apresentando, em média, 23,8\% de polpa. Frutos produzidos no município de Una foram analisados e apresentaram peso médio de $117,40 \mathrm{~g} ; 5,12 \mathrm{~cm}$ de comprimento, $5,82 \mathrm{~cm}$ de diâmetro, 5,95 gomos; 1,1 sementes, 32,5\% de rendimento de polpa, $18,17^{\circ}$ Brix, 18 açúcares solúveis totais, $1,00 \%$ de acidez e pH 2,56. Resultados semelhantes, em termos de características físicas, foram obtidos em frutos produzidos no Estado do Pará (Tabela 2).

Para ser consumido, o fruto precisa ter o seu pericarpo (de 0,5 a 1,0 cm de espessura) cortado cuidadosamente no sentido transversal e a sua parte de cima removida, e os gomos brancos são retirados com garfo ou com palito. Recomenda-se cuidado no corte do fruto, para evitar que a resina contida na casca, que tem forte sabor adstringente, entre em contato com a polpa (Sacramento, 2001).

Várias tentativas têm sido feitas para preservar o fruto na forma de néctar, mas o mangostão é delicado, e o seu sabor é facilmente perdido. O pericarpo contém pectina, tanino e resina amarela. Na China extratos de pericarpo são usados para bronzeamento e tingimento de couro (Yaacob e Tindall, 1995). O córtex do fruto contém tanino, que é utilizado como tintura comercial. O pó do córtex seco é, também, usado no cozimento como adstringente, em casos de disenteria e diarréia crônica. Uma infusão feita das folhas tem sido utilizada no tratamento de ferimentos. A madeira do tronco é de cor marrom-escura e tem sido usada na construção de mobílias.

A casca do mangostão, que representa quase $70 \%$ do peso do fruto, apresenta em sua composição uma classe de substâncias, conhecida como xantonas, que tem despertado grande interesse das indústrias de alimentos e farmacêutica. Essas substâncias possuem alto poder antioxidante e agem no organismo humano, trazendo benefícios à saúde. Na casca do mangostão, são encontradas oito xantonas, as quais a "mangostinone" (Asai et al., 1995). Em decorrência dessa característica, o mangostão vem sendo aproveitado integralmente, e diversos produtos são encontrados envolvendo o suco de mangostão, no qual o produto é obtido a partir da trituração do fruto com todas as suas partes (casca, polpa e sementes). Outras formas envolvem a mistura desse produto com os sucos do noni (Morinda citrifolia L.), do goji (Lycium barbarum L.) e do açaí (Euterpe oleracea Mart.). Tais frutos têm conquistado novos mercados, pelas suas supostas propriedades nutracêuticas. Cápsulas contendo extrato da casca de mangostão também são encontradas no mercado.

\section{5- Metas a serem alcançadas pela pesquisa}

O mangostanzeiro, embora propagado sexuadamente, não apresenta variabilidade genética, devido a sua formação apomítica. Desse modo, as pesquisas deveriam concentrar-se em estudos que permitam o adensamento de plantas com a utilização de mudas propagadas vegetativamente. A nutrição mineral equilibrada, além de proporcionar maior desenvolvimento inicial das mudas, poderia reduzir o índice de frutos nãocomercializados por causa do tamanho e de problemas com estouro de vasos. O raleamento permitiria a produção de frutos mais graúdos, os quais obtêm melhor preço no mercado. Atualmente, o maior problema do cultivo, na região sul da Bahia, é a murcha-do-mangostanzeiro, que mata somente árvores produtivas, cujo agente causal ainda não foi identificado. Aspectos relativos à pós-colheita do mangostão já foram bem estudados em outros países produtores, e as tecnologias podem ser utilizadas no Brasil. Entretanto, estudos farmacológicos poderiam ser efetuados para viabilizar para uso medicinal o aproveitamento da casca de frutos não-comercializados.

TABELA 2 - Características físicas do mangostão produzido no Pará.

\begin{tabular}{lccc}
\hline \multirow{2}{*}{ Características do fruto } & \multicolumn{3}{c}{ Valor } \\
\cline { 2 - 4 } & Médio & Mínimo & Máximo \\
\hline Peso (g) & 103,5 & 56,6 & 169,4 \\
Comprimento do pedúnculo (cm) & 6,7 & 8,0 & 6,9 \\
Diâmetro longitudinal & 4,9 & 5,8 & 8,1 \\
Diâmetro transversal & 6,0 & 7,3 & 7,9 \\
Espessura da casca (cm) & 0,9 & 0,7 & 1,1 \\
Número de secções (gomos) & 6,0 & 3,0 & 8,0 \\
Número de sementes & 1,2 & 0,0 & 4,0 \\
Número de sementes abortadas & 5,2 & 1,0 & 8,0 \\
Sépalas e pedúnculo (\%) & 3,5 & 3,5 & 1,3 \\
Casca (\%) & 69,6 & 58,3 & 81,3 \\
Polpa (\%) & 24,1 & 10,7 & 36,0 \\
Sementes (\%) & 2,8 & 0,9 & 5,6 \\
\hline
\end{tabular}

Fonte: dados não publicados (Urano de Carvalho).

\section{3-Referências}

ALMEYDA, N.; MARTIN, F.W. Cultivation of neglected tropical fruits with promise. Mangosteen: Agriculture Research Service, 1976. part 1, 18p.

ASAI, F.; TOSA, H.; TANAKA, T.; INUMA, M. A Xanthone from pericarps of Garcinia mangostana. Phytochemistry, Oxford, v.39, n.4, p.943-944. 1995.

BARROSO, G.M.; PEIXOTO, A.L.; ICHASO, C.L.F.; GUIMARÃES, E.F.; COSTA, C.G. Sistemática de angiospermas no Brasil. 2. ed. Viçosa: UFV, 2002. v.1, 309p.

BEZERRA, J.L., SACRAMENTO, C.K., ALMEIDA, O.C., BEZERRA, K.M.T. Ocorrência de murcha do mangostãozeiro (Garcinia mangostana L.) na região sul da Bahia. In: SEMINÁRIO DE PESQUISA E PÓS-GRADUAÇÃO DA UESC, 7., 2003, Ilhéus. Anais... (no prelo) 
BRUMMIT, R. K. Vascular plant families and genera. Kew: Royal Botanic Gardens, 1992. 804p.

CRONQUIST, A. A integrated system of classification of flowering plants. New York: Columbia Un. Press, 1981. 520p.

DONADIO, L.C., NACHTIGAL, J.C., SACRAMENTO, C.K.. Frutas exóticas. Jaboticabal: FUNEP, 1998. 279p.

ENOCH, I.C. Morphology of germination. In: CHIN, H.F.; ROBERTS, E.H. Recalcitrant crop seeds. Malaysia: Tropical Press, 1980. p.6-37.

MÜLLER. C.H.; CALZAVARA, B.B.G. GUIMARÃES, A.D.G. Mangostão. Brasília: EMBRAPA-CPATU, 1989 (Recomendações Básicas, 14).

MÜLLER, C.H.; FIGUEIREDO, F.J.C.; MÜLLER, N.R.M., Armazenamento de sementes de mangostão. Belém: EMBRAPA-CPATU, 1991.15p. (Circular Técnica, 58).

MÜLLER, C.H.; FIGUEIREDO, F.J.C.; NASCIMENTO, W.M.O. do: CARVALHO, J.E.U. de; STEIN, R.L.B.; SILVA, A. de B.; RODRIGUES, J.E.L.F. A cultura do mangostão. Brasília: EMBRAPA-SPI, 1995. 56p. (Coleção Plantar, 28).

NUNES, M.A.L.; NUNES, A.L.M. Queima-do-fio em mangustão (Garcinia mangostana) causada por Koleroga noxia. Fitopatologia Brasileira, Brasília, v.20, p.292, 1995. Suplemento

ROBERTS, E.H.; KING, M.W. The characteristics of recalcitrant seeds. In: CHIN, H.F.; ROBERTS, E.H. Recalcitrant crop seeds. Kuala Lampur: Ed. Tropical Press, 1980. p.1-5.

SACRAMENTO, C.K. Mangostãozeiro (Garcinia mangostana L.) Jaboticabal: Sociedade Brasileira de Fruticultura, 2001. 66p. (Série Frutas Potenciais).

SACRAMENTO, C.K.; COELHO JUNIOR., E. Cultivo do mangostão na Bahia. Bahia Agrícola, Salvador, v. 7, n.1, p. $15-18,2005$.

YAACOB, O.; TINDALL, H.D. Mangosteen cultivation. Roma: FAO, 1995. 103p. (Plant Production and Protection Paper, 129) 